\title{
The Study of Law of Distribution by Pipe Length and Transparency on Transportation of Cotton with Pneumatic Transport
}

\author{
Sidikov Akbarhon Khojiakhmadkhonovich ${ }^{1 *}$, Karimov Nuriddin Makhamadjonovich ${ }^{1}$, Abdusattarov \\ Bunyod Karimjonovich ${ }^{1}$, Sarimsakov Olimjon Sharipjanovich ${ }^{2}$ \\ ${ }^{1}$ Researcher, Department of Technological machines and equipment Namangan Institute of Engineering and Technology, \\ Namangan, Uzbekistan, 160115 \\ 2, Professor, Department of Technology of primary processing of natural fibres, Namangan Institute of Engineering and \\ Technology, Namangan, Uzbekistan, 160115 \\ * sidikov_akbarxon@mail.ru
}

\section{ABSTRACT}

The article examines pneumatic transport, one of the main functions of equipment in the sequence of technological processes in ginneries, and gives the main performance of equipment in the pneumatic transport system. Also, the efficiency of the process of transporting cotton in a pneumatic transport device, time of transportation, the share of raw cotton in the internal volume of the air pipeline during transportation and processes in the pneumatic transport system were analyzed on the basis of theoretical and practical experience.

Keywords

cotton, pneumatic transport, fan, air duct, air, length, mass, density, volume, separator.

\section{Introduction}

Preliminary processing of cotton in the technological process requires the improvement of technological processes through the application of in-depth research to the production of efficient designs of pneumatic transport devices [1].

The technological system of primary processing of cotton consists of the process of transportation of raw materials and finished products in the territory and departments of the enterprise by various means of transport [2,3]. At the same time, pneumatic transport is one of the main devices used for the transfer of cotton from gin and closed warehouses to production, as well as for transportation from one department to another. Pneumatic transport differs from other devices by the reliability of the operating system, low losses in transporting cotton, compactness, ease of installation in small spaces, high capacity for transporting cotton in inconvenient conditions, compactness and ultimate simplicity of the repair process. Also, the movement of cotton by airflow contributes to its shrinkage and a slight release of moisture from the product $[4,5]$.
Suction pneumatic vehicles are the main equipment for ginning cotton in ginneries.

The growth of the cotton harvest and cotton production puts before the ginning industry the need to increase production capacity, equipment efficiency and finished product quality. The solution of these problems also depends in many ways on the operation of pneumatic transport of cotton, as it is the main technological process of primary processing of cotton. The moisture content of the cotton harvested during the cotton harvest, the high level of pollution and the increase in the volume of production lead to the expansion of the area under the enterprise. As a result, the intermediate length of the means of transport within the enterprise increases [6,7].

One of the main requirements in the technological system of ginneries is the preservation of its natural properties in the transportation of seed cotton. Therefore, many researchers involved in the study of cotton pneumatic transport have focused on the study of seed injury. 


\section{The Main Issue}

Pneumatic transport devices are used in industrial enterprises for the transportation of raw materials and products within the enterprise. There are suction, spray and mixed types of these devices, and suction-type pneumatic transport devices are mainly used in ginneries. In ginneries, pneumatic transport equipment delivers cotton from the gins to the production shops, transfers it from one shop to another, as well as from one point to another within one shop [8].

Analyzes show that in existing ginneries, raw cotton is repeatedly transported by pneumatic transport. Depending on the location and proximity of the workshops and cotton gins at the enterprise, the number of pneumo-transport passes of cotton is 4-6.

Depending on the proximity of the transport distance, centrifugal fans are used as mainly the label of VTs-8M, VTs-10M, VTs-12M [11], the capacity power is $30,55,75 \mathrm{~kW} / \mathrm{h}$, the airflow is $3.5,5.5,6.4 \mathrm{~m}^{3} / \mathrm{s}$, in pneumatic devices. Steel pipes with a thickness of $2-3 \mathrm{~mm}$ and an inner diameter of $0.4 \mathrm{~m}$ are used as material conductors (air pipes).

In many studies, the pneumatic transport elements of raw cotton, as well as the laws of movement within the air duct have been studied at different levels $[9,10]$. In the research, we raise a slightly different issue - we analyze the process of transporting cotton by pneumatic transport, based on engineering calculations based on the laws and indicators identified in our current and previous research.

Material handling efficiency is one of the main indicators of a pneumatic machine. It is defined as follows:

$$
P=\frac{M}{t}
$$

here: M- the weight of cotton; t-shipping time.

The change in the mass of cotton along the entire length 1 of the entire air duct should be determined using the following integral:

$$
M=\pi R^{2} \int_{0}^{L}(1-m) \gamma d x
$$

Here $m$ is the porosity of the medium (raw cotton), which must be determined by the flow equation. If the initial transfer rate of the raw material is $v_{0}$ and the velocity in any section of the air duct is $v$, then the following equation is valid in the stationary transfer mode:

$$
1-m=\left(1-m_{0}\right) v_{0} \gamma_{0} / \gamma v
$$

Here $m_{0}$ and $\gamma_{0}$ are the porosity and density of the raw cotton at the entrance to the air duct, $v$ and $\gamma$ are the velocities and densities of the raw material at any section of the air duct, which are determined using the additional equations explained above. If the density and velocity of the raw material along the airline do not change, then the equations $v=v_{0}, \quad \gamma=\gamma_{0}, \quad m=m_{0}$ and $M=\pi R^{2}\left(1-m_{0}\right) L \gamma_{0}$ are valid, and the volume of the raw material is as follows:

$$
V=M / \gamma_{0}=\pi R^{2}\left(1-m_{0}\right) L
$$

Since the volume of the air pipe is $V \_k=\pi R^{\wedge} 2 L$, the share of the volume of raw material along the air pipe (in per cent) is $\mathrm{V} / \mathrm{V} \_\mathrm{k}=\left(1-\mathrm{m} \_0\right) 100$. If, at the transmission limit, $\mathrm{m} 0=0.7(70 \%) \mathrm{v}=\mathrm{v} \_0$ (the speed of the raw material is equal to and constant with the speed of its transmission), the raw material occupies $30 \%$ of the volume of the pipeline. If the velocity of the raw material increases to $v=n v_{0}(n \geq 1)$ and is assumed to be $\gamma=\gamma_{0}$, then we obtain the equation $V / V_{k}=\left(1-m_{0}\right) / n$. In particular, when $m_{0}=0.7, n=1.5$, the raw material occupies $20 \%$ of the volume of the air duct, that is, as the speed of the raw material increases, its shredding and splitting takes place. Although the obtained equations express the general laws of the process of transportation of cotton by pneumatic transport, they do not reflect the real situation in it. Therefore, in the analysis of pneumatic transport processes, the efficiency of the transport process depends on the final element of the pneumatic structure - the working efficiency of the separator (also called the capacity of the indicator).

The existing separator equipment has the following performance:

SS-15A separator - $15 \mathrm{t} / \mathrm{h}$.

SX separator - $22 \mathrm{t} / \mathrm{h}$.

Several researchers have proposed modern methods of improving the technological process by changing the separation equipment of the 
separator CC-15A [12]. Technological machines, for example, drying drum (model 2 SB-10, SBO) $10 \mathrm{t} / \mathrm{h}$, fine cleaning machines UXK and $1 \mathrm{XK}$ models 5-7 t/h, fibre separators (battery) have a capacity of around $10 \mathrm{t} / \mathrm{h}$. Variations in the productivity of process machines cause excess cotton to accumulate in front of low-productivity machines when they are operating at full capacity. This, in turn, over-occupies the working areas, which is not advisable in the event of a fire hazard. Therefore, we make calculations based on the average productivity of most machines $-\mathrm{P}=$ $10 \div 12 \mathrm{t} / \mathrm{h}$.

If we convert the productivity from $t / h$ to $\mathrm{kg} / \mathrm{s}: P$ $=(10 \div 12) \mathrm{t} / \mathrm{s}=2.78 \div 3.33 \mathrm{~kg} / \mathrm{s}$. Shipping time can be determined as follows:

$$
t=\frac{l}{v_{m}}
$$

here: $v_{M}$ - material (cotton) velocity, $\mathrm{m} / \mathrm{s}$; 1transport distance (length of air pipeline). From this, after a simple form change, we get:

$$
\mathrm{M}=\frac{\Pi \cdot l}{V_{M}}
$$

Here is the weight of cotton corresponding to the length $l$ of the M-air tube. This equation applies under the following conditions: $l>0 ; v_{m}>0$.

\section{Results}

Studies have determined the velocities of cotton and air at the top of the pipe. At the first $1 \mathrm{~m}$ distance, the speed of the cotton will be close to the speed of the conveyor belt. The speed of the conveyor belt in use is $3 \mathrm{~m} / \mathrm{s}$. At the end of a distance of $1 \mathrm{~m}$, the speed of cotton reaches 4.5 $\mathrm{m} / \mathrm{s}$. Assuming an average value of velocity, $v_{m}=$ $3.5 \mathrm{~m} / \mathrm{s}$. In that case, when the work productivity is $\mathrm{P}=2.78 \mathrm{~kg} / \mathrm{s}, l=1 \mathrm{~m}$.

$$
M=\frac{2.78 \cdot 1}{3.5}=0.8 . \kappa 2
$$

When $\mathrm{P}=3.33 \mathrm{~kg} / \mathrm{s}, l=1 \mathrm{~m}$.

$$
M=\frac{3,33 \cdot 1}{3.5}=0.95 \kappa 2
$$

According to the figures obtained, only $0.80 \div$ $0.95 \mathrm{~kg}$ of cotton per $1 \mathrm{~m}$ of air pipeline is transported by pneumatic transport.

Studies have shown that the density of cotton coming out of the gin is around $\gamma=36 \mathrm{~kg} / \mathrm{m}^{3}$, and if the mass of cotton is $\mathrm{M}=0.79 \div 0.95 \mathrm{~kg}$, the volume of such a body is as follows:

$$
V=M / g=(0.79-0.95) / 36=0.022-0.026 \mu^{3} \text {. }
$$

The volume of $1 \mathrm{~m}$ length of air pipe is $V_{K}=1 \cdot \pi$. $r^{2}=1 \cdot 3.14 \cdot 0.2^{2}=0.1256 \mathrm{M}^{3}$. If we find their percentage:

$$
V \%=(17,6-20,7) \% .
$$

Then the speed of the cotton increases and the speed of the air decreases. At a distance of 50 meters, the porosity of cotton increases 2 times (from 0.4 to 0.8 ), while its density decreases by 2 times $\left(\gamma=36 / 2=18 \mathrm{~kg} / \mathrm{m}^{3}\right)$, the speed of cotton reaches $9 \div 10 \mathrm{~m} / \mathrm{s}$ (hence the average speed around $v_{m}=6.5 \mathrm{~m} / \mathrm{s}$ ), the air velocity decreases to about $15 \mathrm{~m} / \mathrm{s}$. Let's consider according to them:

$$
M=\frac{(2.78 \div 3.33) \cdot 50}{6.5}=21.38 \div 25.62 \mathrm{~kg}
$$

The volume occupied by cotton is $V=M / \gamma$ $=(21.38 \div 25.62) / 18=1.19 \div 1.42 \mathrm{M}^{3}$. The volume of $50 \mathrm{~m}$ air pipe will be $V_{K}=50 \cdot 0.1256=6.28 \mathrm{M}^{3}$. Let's find their ratio:

$$
V \%=(19,0-22,6) \%
$$

Analyzing the results obtained (Fig. 1), when transporting cotton by pneumatic transport, if it is assumed that the cotton is transported evenly, the cotton occupies only $18 \div 23 \%$ of the pipe volume when spread along the length of the air pipe. These calculations show that the main part of the air duct remains empty when transporting cotton by pneumatic transport.

Of course, this part is busy with air and has great carrier potential. If we take into account that the velocities of air and material in the calculations are much lower than the calculated values, our opinion that the power of pneumatic transport is used inefficiently seems more reasonable. 


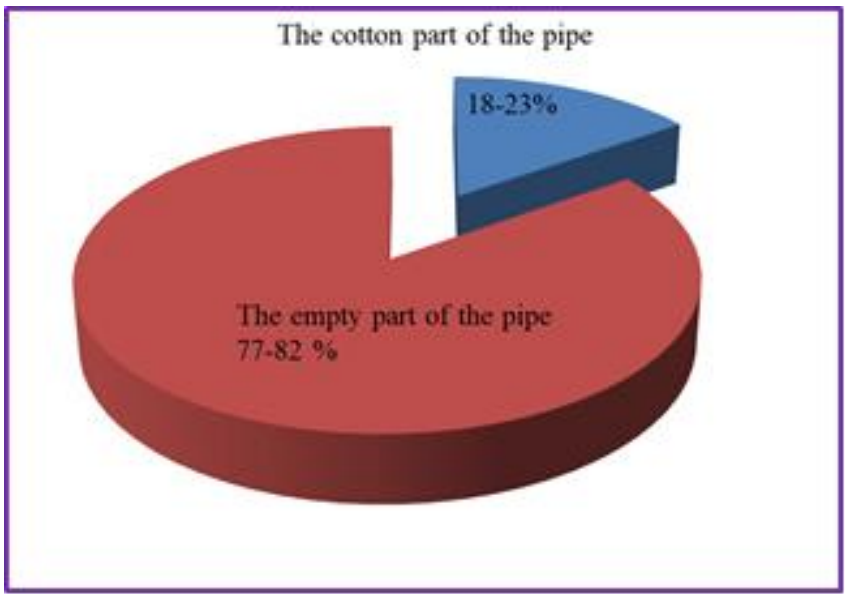

\section{Figure 1. The share of raw cotton in the volume of the air duct during transportation}

An increase in the cross-section of the air duct at the same air velocity leads to a large increase in air consumption, and consequently to a decrease in power consumption, and a decrease in air consumption and power. From this, it can be concluded that the actual diameter of the pneumatic transport pipe $d=0.4 \mathrm{~m}$ is much higher than required. By increasing the concentration of cotton in the air transport, it is possible to increase the utilization rate of the air transport pipe volume, and in this way, it is possible to reduce the amount of air and energy corresponding to the unit product.

This diameter of the air duct is based on the fact that it prevents clogging of the cotton at the beginning of the pipe as a result of uneven, large layers of transmission and facilitates the formation of an air mixture at the beginning of the air duct. Accordingly, ensuring that the cotton is coated and uniformly distributed ensures that the air duct is not clogged and that the material moves easily within the air duct, even at smaller diameters than the actual air duct.

With an effective air velocity of $20 \div 25 \mathrm{~m} / \mathrm{s}$, the airflow rate is $\mathrm{Q}=\mathrm{FV}=1.9 \div 2.4 \mathrm{~m}^{3} / \mathrm{s}$ if the air pipe diameter is $315 \mathrm{~mm}$, and $\mathrm{Q}=\mathrm{FV}=1.4 \div 1.8$ $\mathrm{m}^{3} / \mathrm{s}$ if it is $355 \mathrm{~mm}$. decreases. Studies by H.T. Akhmedkhodjaev and S. Kadyrkhodjaev show that at this speed of air, cotton moves mainly in the lower part of the air duct, in contact with the air duct, in the form of jumps. This in turn has a negative impact on cotton quality. According to the results obtained by the authors, cotton moves suspended in an air tube at a speed of $28 \mathrm{~m} / \mathrm{s}$ and above. Therefore, we recommend choosing a carrier air velocity of $28-30 \mathrm{~m} / \mathrm{s}$. To do this, we have the opportunity to increase the airspeed without excessive energy consumption, because the small diameter of the air duct is selected.

In that case, if the airflow rate is $3.14 \mathrm{~m}^{3} / \mathrm{s}$ at an air pipe diameter of $400 \mathrm{~mm}$ and a velocity of 25 $\mathrm{m} / \mathrm{s}$, then $\mathrm{Q}=\mathrm{FV}=2.87 \mathrm{~m}^{3} / \mathrm{s}($ or $8.6 \%)$ at an air pipe diameter of $355 \mathrm{~mm}$ and a speed of $29 \mathrm{~m} / \mathrm{s}$. low), the airflow diameter is $315 \mathrm{~mm}$, and the airflow rate is $\mathrm{Q}=\mathrm{FV}=2.26 \mathrm{~m}^{3} / \mathrm{s}$ (or $28 \%$ less) when the speed is $29 \mathrm{~m} / \mathrm{s}$. This, in turn, allows the expansion of the operating range of the pneumatic vehicle, or the use of a lower-power fan instead of a high-power fan, and saves electricity.

For example, if a fan VTs-10M is installed instead of VTs-12M, energy consumption can be reduced by $20 \mathrm{~kW} / \mathrm{h}$, and if a fan VTs-8M [11] is installed instead of VTs-10M, it can be reduced by 19 $\mathrm{kW} / \mathrm{h}$. If we take into account the fact that cotton passes through pneumatic transport equipment many times, these figures will be higher, that is, if the recommendations are applied to all pneumatic transport equipment in the enterprise, it will save 4-6 times more electricity.

The transition to the use of small-sized air ducts, in turn, will reduce the cost of cleaning the exhaust air, the release of fibers in the exhaust air, metal consumption and further increase the operational characteristics of pneumatic transport equipment.

\section{Conclusion}

1. When transporting cotton by pneumatic transport, if it is assumed that the cotton is being transported evenly, the cotton will occupy only 18 to 23 per cent of the pipe volume when spread along the length of the air pipe, leaving the main part of the air pipe empty.

2. By increasing the concentration of cotton in the air transport, it is possible to increase the utilization rate of the air transport pipe volume, and in this way, it is possible to reduce the amount of air and energy per unit product.

3. An increase in the cross-section of the air duct at the same air velocity leads to a large increase in air consumption, and consequently to a decrease 
in air consumption and power. Accordingly, the smaller the diameter of the pneumatic conveyor pipe, the lower the air and energy consumption.

\section{Acknowledgement}

Authors acknowledge the immense help received from the scholars whose articles are cited and included in references to this manuscript. The authors are also grateful to authors/ editors/publishers of all those articles, journals and books from where the literature for this article has been reviewed and discussed.

\section{References}

[1] Obidov, A., Akhmedhodjaev, K., Sarimsakov, O., \& Holikov, Q. (2018). Investigation of the Properties of Fibrous Cotton Seeds, for Sorting on a Mesh Surface. Engineering, 10(09), 572.

[2] Abdukarimovich, M. O., Ibragimovich, A. K., \& Sharipjanovich, S. O. (2018). Designing a New Design of a Loading Cylinder for Pneumomechanical Spinning Machines. Engineering, 10(06), 345.

[3] Tursunov, I., Rajapova, N., Sarimsakov, O., \& Mardonov, B. (2019). The Movement of a Mixture of Cotton with an Air Stream during Pneumatic Transport by Pipeline of Variable Cross Section. Engineering, 11(8), 531-540.

[4] Korabayev, S. A., Matismailov, S. L., \& Salohiddinov, J. Z. (2018). Investigation of the impact of the rotation frequency of the discretizing drum on the physical and mechanical properties of. Central Asian Problems of Modern Science and Education, 3(4), 65-69.

[5] Korabayev, S. A., Mardonovich, M. B., Lolashbayevich, M. S., \& Xaydarovich, M. U. (2019). Determination of the Law of Motion of the Yarn in the Spin Intensifier. Engineering, 11(5), 300-306.

[6] Sarimsakov, O. (2016). The Possibility of Reducing Cotton Consumption in Cotton. American Journal of Science and Technology, 4, 68-72.

[7] Sarimsakov, O., Xusanov, C., \& Muradov, R. (2016). The Change in Air Pressure Along the Length of the Pipeline
Installation for Pneumatic Conveying of Raw Cotton. Journal of Engineering and Technology, 3, 89-92.

[8] Ahmadjanovich, K. S., Lolashbayevich, M. S., \& Tursunbayevich, Y. A. (2020). Study Of Fiber Movement Outside The Crater Of Pnevmomechanical Spinning Machine. Solid State Technology, 63(6), 3460-3466.

[9] Tojimirzayev, S.T, Parpiyev, D.X, \& Omonov, M.T (2020). Исследование изменений свойств волокон по переходам в процессе прядения. [In Russian: Investigation of changes in fiber properties by transitions during spinning] Universum: tehnicheskie nauki, (6-2 (75)), 50-56.

[10] Erkinov, Z., Jumaniyazov, K., Parpiyev, X., Fayzullaev, Sh., \& Jamalov, B. (2016). Влияние числа сложений одиночных нитей, выработанных по различным системам прядения, на качество крученой нити. [In Russian: Influence on the number of complex odinochnyh threads, developed on different systems of pryadeniya, on the quality of the threaded thread] In Modelirovanie $v$ tehnike $i$ jekonomike (pp. 201-203).

[11] Справочник | RIM-KOLOSS. (n.d.). ATON TIMES. Retrieved February 4, 2021, from http://www.rimkoloss.uz/form/6

[12] Cenapamop CC15A в Ташкент. (n.d.). Paxtamash.Gl.Uz. Retrieved February 4, 2021, from https://paxtamash.gl.uz/ru/separator-ss15a157136/ 